\title{
The importance of promoting physical activity during the COVID-19 outbreak to control the worsening of old pandemics
}

\author{
ISABELA R. MARÇAL ${ }^{1}$ | EMMANUEL G. CIOLAC ${ }^{1}$ \\ ${ }^{1}$ Exercise and Chronic Disease Research Laboratory (ECDR), Departament of Physical Education, School of Sciences, São Paulo State University - UNESP, Bauru, SP, \\ Brazil. \\ Correspondence to: Emmanuel Gomes Ciolac. Universidade Estadual Paulista - UNESP, Faculdade de Ciências, Departamento de Educação Física, Laboratório de \\ Pesquisa em Exercício Físico e Doenças Crônicas. Av. Engenheiro Luiz Edmundo Carrijo Coube 14-06, Bauru, Brazil, 17033-360. \\ e-mail: emmanuel.ciolac@unesp.br | Twiter: @ProfessorCiolac \\ https://doi.org/10.20338/bjmb.v15i1.217
}

\author{
HIGHLIGHTS \\ - The measurements to contain COVID-19 are \\ changing the daily living activities in the \\ general population. \\ - A combination of a past and present \\ pandemics can be dangerous, and new \\ strategies are necessary. \\ - Physical activity is one of the most important \\ non-pharmacological therapies for health \\ promotion, and for prevention and \\ management of diseases. \\ - There is an urgent need in changing the face- \\ to-face prescription, management, and \\ evaluation of exercise to remote tools. \\ - The transitions from center-based to home- \\ based training are welcome to control the \\ worsening of old pandemics.
}

ABSTRACT: The pandemic of coronavirus disease 2019 (COVID-19) is an unprecedented public health emergency of global concern. Although the measures to contain the COVID-19 spreading is essential, there are old pandemics that we are still fighting and cannot be neglected during the current outbreak. Non communicable chronic diseases (NCDs) remain the leading cause of death worldwide. Indeed, physical inactivity is one of the most important risk factors for NCDs and it was considered a pandemic matter in 2012. Therefore, we discuss new strategies (i.e., transition from center-based to home-based training) to increase motivation, participation, and adherence in physical activity during the COVID-19 to control the worsening of old pandemics.

KEYWORDS: COVID-19 | Non-communicable chronic diseases | Physical activity | Home-based training

\section{INTRODUCTION}

The COVID-19 is an emergency that is responsible for 150.814 .990 million infections and 3.171.266 deaths worldwide. ${ }^{1}$ The severe acute respiratory syndrome coronavirus 2 (SARS-CoV-2) has been shown to affect most individuals with noncommunicable chronic diseases (NCDs) resulting in poorer outcomes and higher mortality. ${ }^{2}$ NCDs has been considered a global health issue by the World Health Organization (WHO) for the last 15 years. ${ }^{3}$ NCDs represented US\$ 84 billion of costs in low-and-middle-income countries whereas it was accountable for $50 \%$ of the disease's total burden. ${ }^{3}$ Indeed, although the measures to contain COVID-19 spreading are urgent 
and welcome, there are old pandemics that we are still fighting and cannot be neglected during the current outbreak.

Physical inactivity is highly related to NCDs and it was considered a pandemic matter in $2012 .{ }^{4}$ In 2013, it was responsible for US\$ 13.7 billion in productivity losses and 13.4 million disability-adjusted life-years worldwide..$^{5}$ Therefore, many international and national organizations were "called to action" to advance global health through physical activity. ${ }^{6}$ Public strategies aimed to reduce at least $10 \%$ of physical inactivity until $2025 .{ }^{7}$ However, the prevalence of insufficient levels of physical activity has been increasing in low-income countries during the last years. ${ }^{5}$ Therefore, it may not be possible to reach this goal in the upcoming five years. ${ }^{8}$

Furthermore, the measurements due to the COVID-19 (i.e., lockdown, quarantine, and social isolation) are changing the daily living activities of worldwide population. ${ }^{9}$ Preliminary evidence suggests a decrease in physical activity levels and a rise in sedentary behavior, which may substantially increase the burden of NCDs. ${ }^{10}$ Nevertheless, aging population is an increasingly worldwide phenomenon, and the age-related effects have been demonstrating to affect motor performance (i.e., slowing of movement) and cognitive deficits (i.e., working memory) in older individuals. These declines in fine motor control, gait, and balance affect the ability of older adults to perform activities of daily living and thus maintain their independence. ${ }^{11}$ In addition, the perception of social isolation (i.e., loneliness) is also a psychological risk factor for mortality and morbidity. ${ }^{12}$ It has been demonstrated that loneliness and social isolation are strongly associated with cardiovascular conditions such as hypertension and atherosclerosis. Indeed, this continuous social stress can influence cognitive function, depression, overactivation of the sympathetic nervous system, and disturb neuroendocrine mechanisms. ${ }^{13}$ Thus, a combination of the current pandemic and a lockdown environment can be dangerous and strategies to improve physical and mental health are urgently required.

Physical activity is one of the most important non-pharmacological therapies in health promotion, prevention, and management of diseases. ${ }^{6}$ The numerous benefits in health-related and psychosocial variables are well established.6,14 The chronic benefits of the regular practice of physical activity are constructed by single sessions of exercise. For example, in neurodegenerative diseases, one single session of a high- and moderateintensity aerobic exercise has demonstrated to promote better cognitive performance in people with Parkinson's disease (PD). ${ }^{15}$ However, regarding to chronic effects, 12 weeks of high-intensity interval exercise were superior to moderate-intensity continuous exercise in improving the six-minute walking test and endothelial function in PD. ${ }^{16}$ In cardiovascular diseases, aerobic exercises can acutely reduce systolic/diastolic blood pressure nearly by $8 / 9 \mathrm{mmHg}$, respectively. ${ }^{17}$ In the long-term, a reduction of $36 / 12 \mathrm{mmHg}$ in systolic/diastolic blood pressure can be observed. ${ }^{18}$ In fact, only a small reduction of $5 \mathrm{mmHg}$ in systolic blood pressure decreases the risk of stroke by $14 \%$, coronary heart disease by $9 \%$, and all-cause mortality by $7 \% .{ }^{19}$ Hence, the benefits of exercise initiate with short steps in different diseases and it should be emphasized to increase the individuals' participation, motivation, and adherence to physical activity.

The main recommendations for physical activity are based on the frequency, intensity, time, and type (FITT) of at least $150 \mathrm{~min}$ (30 min, $5 \mathrm{~d} / \mathrm{wk}$ ) of moderate-intensity exercise (40-60\%VO2MAX) or $75 \mathrm{~min}$ ( $25 \mathrm{~min}, 3 \mathrm{~d} / \mathrm{wk}$ ) of high-intensity exercise $(60-85 \%$ ofVO2MAX) per week, in association with 2 to 3 sessions per week of resistance 
exercise. ${ }^{14}$ Flexibility and balance training are also recommended (2-3 d/wk), mostly for older individuals. ${ }^{6}$ However, the implementation of the physical activity guidelines' recommendations in the general population is challenging. The main barriers correlated with adult's participation in physical activity are concerning the influence of marital status, obesity, smoking, lack of time, past exercise behavior, and environmental variables. ${ }^{20}$ Hence, access to facilities, neighborhood safety, and access to exercise equipment at home can be important factors for increasing participation and supporting behavioral change. ${ }^{20,21}$

In recent years, home-based exercise training has been investigated as an alternative to center-based training programs (i.e., gym, parks, clubs), and has been shown to be an effective tool for improving cardiometabolic and psychosocial variables, with no adverse events being reported. ${ }^{21,22}$ In addition, it may aid patients in developing self-management skills for improving and maintaining their physical fitness levels. ${ }^{23}$ However, the benefits of home-based exercise training for high-risk individuals (i.e., cardiovascular disease) is still not adequately elucidated in the literature and future studies are needed. Moreover, with the first wave of COVID-19, there was an urgent need to change the face-to-face prescription, management, and evaluation of exercise to remote tools (i.e., apps, videos, games, and other technologies). ${ }^{21,24}$ With the second wave of the COVID-19 in different countries, essential transitions from center-based to home-based were welcomed to be developed and implemented focusing on new alternatives, and thus increasing motivation, participation, and adherence to physical activity for controlling the worsening of old pandemics (i.e., physical inactivity).

A recent review demonstrated the usefulness and safety of home-based exercise training including aerobic, resistance, or combined exercise programs in individuals with diabetes. ${ }^{24}$ Various tools such as heart rate monitors, pedometers, portable oximeters, questionnaires, diaries, or scales were suggested to control the intensity and duration of exercise. ${ }^{24}$ In addition, the use of equipment such as cycle ergometer, home rowing ergometer, stairs, chair, rice bags, and bottles of water were mentioned as practical strategies to implement an adequate exercise program. ${ }^{24}$ It is important to note that regular phone calls, video conferences, reevaluations, visits, cellphone messages, apps advice, emails, or internet devices are considered important to maintain the development and the regular feedback. ${ }^{21,24} \mathrm{~A}$ first orientation session with explanations about an exercise program and self-management education (i.e., call to the emergency in case of an event or injury) is relevant during a well-guided home-based exercise program. ${ }^{22}$ Yet, a multidisciplinary team is important in the management and security of these programs.

The main advantages of home-based exercise training are expanded access, individual programs, flexible scheduling, privacy, integration with regular home routines, and members of the family. ${ }^{21}$ Moreover, home-based exercise training has been associated with higher satisfaction and appears to be more cost-effective than centerbased training. ${ }^{23}$ Thus, it should be considered as a fixed option within exercise programs, based on the preference, sociodemographic conditions, and clinical status of each participant. Nonetheless, the latest WHO guidelines of physical activity and sedentary behavior emphasize that "doing some physical activity is better than doing none" and "every movement count" for all populations. ${ }^{25}$ In this context, small actions in daily living, such as interrupting prolonged sitting every $30 \mathrm{~min}^{26}$ or regular intermittent bouts of vigorous-intensity incidental physical activity (i.e., carrying shopping bags, walking uphill, 
and stair climbing) are beneficial for health and should be encouraged in lifestyle behavior during and beyond home-based exercise training. ${ }^{27}$

Finally, while many international strategies are being developed to contain the COVID-19, ${ }^{1}$ it is still necessary to combat old pandemics as the burden of NCDs and physical inactivity. Despite the lack of studies assessing the health impact during the COVID-19, physical inactivity can have an important impact, including an increase in the global burden of NCDs. Therefore, increasing participation, adherence, and maintaining the levels of physical activity will provide long-term physical, motor, and psychosocial benefits. Indeed, the transition from center-based to home-based exercise programs may be a useful and safe strategy during and beyond the COVID-19 outbreak, and future studies to elucidate these benefits in the general population are welcome. In conclusion, physical activity should be considered as the key to the past, present, and future which have important public health implications.

\section{ACKNOWLEDGMENTS}

This work was supported in part by the Fundação de Amparo à Pesquisa do Estado de São Paulo [FAPESP \#2018/09695-5 - FAPESP \#2019/19596-7], the Conselho Nacional de Desenvolvimento Científico e Tecnológico [CNPq \#303399/2018-0], and the Coordenação de Aperfeiçoamento de Pessoal de Nível Superior - Brasil (CAPES Finance Code 001).

\section{REFERENCES}

1. World Health Organization. Coronavirus disease (COVID-19) outbreak. https://www.who.int/westernpacific/emergencies/covid-19. Accessed February 12, 2021.

2. Mehra MR, Desai SS, Kuy S, Henry TD, Patel AN. Cardiovascular Disease, Drug Therapy, and Mortality in Covid-19. N Engl J Med. 2020:1-8. 10.1056/NEJMoa2007621

3. Abegunde DO, Mathers CD, Adam T, Ortegon M, Strong K. The burden and costs of chronic diseases in low-income and middle-income countries. Lancet. 2007;370(9603):1929-1938. 10.1016/S0140-6736(07)61696-1

4. Kohl HW, Craig CL, Lambert EV, et al. The pandemic of physical inactivity: Global action for public health. Lancet. 2012;380(9838):294-305. 10.1016/S0140-6736(12)60898-8

5. Ding D, Lawson KD, Kolbe-Alexander TL, et al. The economic burden of physical inactivity: a global analysis of major non-communicable diseases. Lancet. 2016;388(10051):13111324. 10.1016/S0140-6736(16)30383-X

6. World Health Organization. WHO Global Recommendations on Physical Activity for Health. http://apps.who.int/iris/bitstream/10665/44399/1/9789241599979

7. Stringhini S, Carmeli C, Jokela M, et al. Socioeconomic status and the $25 \times 25$ risk factors as determinants of premature mortality: a multicohort study and meta-analysis of $1 \cdot 7$ million men and women. Lancet. 2017;389(10075):1229-1237. 10.1016/S0140-6736(16)32380-7

8. Guthold R, Stevens GA, Riley LM, Bull FC. Worldwide trends in insufficient physical activity from 2001 to 2016: a pooled analysis of 358 population-based surveys with 1.9 million 
participants. Lancet Glob Heal. 2018;6(10):e1077-e1086. 10.1016/S2214-109X(18)303577

9. Hall G, Laddu DR, Phillips SA, Lavie CJ, Arena R. A tale of two pandemics: How will COVID-19 and global trends in physical inactivity and sedentary behavior affect one another? Prog Cardiovasc Dis. 2020:1-3. 10.1016/j.pcad.2020.04.005

10. Pecanha T, Goessler KF, Roschel H, Gualano B. Social isolation during the COVID-19 pandemic can increase physical inactivity and the global burden of cardiovascular disease. Am J Physiol - Hear Circ Physiol. 2020;318(6):H1441-H1446. 10.1152/ajpheart.00268.2020

11. Seidler RD, Bernard JA, Burutolu TB, et al. Motor Control and Aging: Links to Age-Related Brain Structural, Functional, and Biochemical Effects. Neurosci Biobehav Rev. 2010;34(5):721-733. 10.1016/j.neubiorev.2009.10.005.

12. Cacioppo JT, Cacioppo S, Capitanio JP, Cole SW. The Neuroendocrinology of Social Isolation. Annu Rev Psychol. 2015;66(1):733-767. 10.1146/annurev-psych-010814-015240

13. Xia N, Li H. Loneliness, Social Isolation, and Cardiovascular Health. Antioxidants Redox Signal. 2018;28(9):837-851. 10.1089/ars.2017.7312

14. ACM's. American College of Sports Medicine. ACSM's Guidelines for Exercise Testing and Prescription. 10th Ed.; 2018. 10.1249/00005768-199110000-00024

15. Fiorelli CM, Ciolac EG, Simieli L, et al. Differential acute effect of high-intensity interval or continuous moderate exercise on cognition in individuals with Parkinson's disease. J Phys Act Heal. 2019;16(2):157-164. 10.1123/jpah.2018-0189

16. Fernandes B, Barbieri FA, Arthuso FZ, et al. High-intensity interval versus moderateintensity continuous training in individuals with Parkinson's disease: Hemodynamic and functional adaptation. J Phys Act Heal. 2020;17(1):85-91. 10.1123/jpah.2019-0588

17. MacDonald J. Potential causes, mechanisms, and implications of post exercise hypotension. J Hum Hypertens. 2002;16:225-236. 10.1038/s/j/jh/1001377

18. Guimaraes GV, De Barros Cruz LG, Fernandes-Silva MM, Dorea EL, Bocchi EA. Heated water-based exercise training reduces 24-hour ambulatory blood pressure levels in resistant hypertensive patients: A randomized controlled trial (HEx trial). Int J Cardiol. 2014;:172(2):434-441. 10.1016/j.jijcard.2014.01.100

19. Ettehad D, Emdin CA, Kiran A, et al. Blood pressure lowering for prevention of cardiovascular disease and death: A systematic review and meta-analysis. Lancet. 2016;387(10022):957-967. 10.1016/S0140-6736(15)01225-8

20. Trost S, Neville O, Bauman A, Sallis J, Brown W. Correlates of adults' participation in physical activity: review and update. Med Sci Sport Exerc. 2002:1996-2001. 10.1249/01.MSS.0000038974.76900.92

21. Thomas RJ, Beatty AL, Beckie TM, et al. Home-Based Cardiac Rehabilitation: A Scientific Statement From the American Association of Cardiovascular and Pulmonary Rehabilitation, the American Heart Association, and the American College of Cardiology. J Am Coll Cardiol. 2019;74(1):133-153. 10.1016/j.jacc.2019.03.008 
22. Piotrowicz E, Piepoli MF, Jaarsma T, et al. Telerehabilitation in heart failure patients: The evidence and the pitfalls. Int J Cardiol. 2016;220:408-413. 10.1016/j.jijcard.2016.06.277 227

23. Kraal JJ, Elske Van Den Akker-Van Marle M, Abu-Hanna A, Stut W, Peek N, Kemps HMC. Clinical and cost-effectiveness of home-based cardiac rehabilitation compared to conventional, centre-based cardiac rehabilitation: Results of the FIT@Home study. Eur J Prev Cardiol. 2017;24(12):1260-1273. 10.1177/2047487317710803

24. Marçal IR, Fernandes B, Viana AA, Ciolac EG. The Urgent Need for Recommending Physical Activity for the Management of Diabetes During and Beyond COVID-19 Outbreak. Front Endocrinol (Lausanne). 2020;11(584642):11-11. 10.3389/fendo.2020.584642

25. World Health Organization. WHO Guidelines on physical activity and sedentary behaviour. https://www.who.int/publications/i/item/9789240015128. Published 2020.

26. Ekelund U, Steene-Johannessen J, Brown WJ, et al. Does physical activity attenuate, or even eliminate, the detrimental association of sitting time with mortality? A harmonised meta-analysis of data from more than 1 million men and women. Lancet. 2016;388(10051):1302-1310. 10.1016/S0140-6736(16)30370-1

27. Stamatakis E, Huang BH, Maher C, et al. Untapping the Health Enhancing Potential of Vigorous Intermittent Lifestyle Physical Activity (VILPA): Rationale, Scoping Review, and a 4-Pillar Research Framework. Sport Med. 2020. 10.1007/s40279-020-01368-8

Citation: Marçal IR, Ciolac EG. The importance of promoting physical activity during COVID-19 outbreak to control the worsening of old pandemics. BJMB. 2021:15(1):20-25.

Editors: Dr Fabio Augusto Barbieri - São Paulo State University (UNESP), Bauru, SP, Brazil; Dr José Angelo Barela São Paulo State University (UNESP), Rio Claro, SP, Brazil; Dr Natalia Madalena Rinaldi - Federal University of Espírito Santo (UFES), Vitória, ES, Brazil.

Copyright:@ 2021 Marçal and Ciolac and BJMB. This is an open-access article distributed under the terms of the Creative Commons Attribution-NonCommercial-NoDerivatives 4.0 International License which permits unrestricted use, distribution, and reproduction in any medium, provided the original author and source are credited.

Funding: This work was supported in a part by Fundação de Amparo à Pesquisa do Estado de São Paulo [FAPESP \#2018/09695-5 - FAPESP \#2019/19596-7], Conselho Nacional de Desenvolvimento Científico e Tecnológico [CNPq \#303399/2018-0], and Coordenação de Aperfeiçoamento de Pessoal de Nível Superior - Brasil (CAPES - Finance Code 001).

Competing interests: The authors have declared that no competing interests exist.

DOl: https://doi.org/10.20338/bjmb.v15i1.217 